\title{
Anthropogenic factors as an element of uncertainty in hydrological modelling of water yield with SWAT
}

\author{
R. Corobov ${ }^{1, *}$, G. Syrodoev ${ }^{2}$, I. Trombitsky ${ }^{3}$ and D. Galupa ${ }^{4}$ \\ ${ }^{1}$ EcoTiras International Association of River Keepers, Teatrala 11a, Chisinau, Moldova \\ ${ }^{2}$ Institute of Ecology and Geography, Academii 3, Chisinau, Moldova \\ ${ }^{3}$ EcoTiras International Association of River Keepers, Teatrala 11a, Chisinau, Moldova \\ ${ }^{4}$ Forest Research and Management Institute, Calea Iesilor 69,.Chisinau, Moldova
}

Received 7 April 2016; Accepted 19 May 2016

\begin{abstract}
In 2014 the SWAT (Soil and Water Assessment Tool) model was used as a basis for follow-up investigations of Moldova's small rivers potential flow. The first step of the study included the validation of SWAT for local conditions. As an experimental area, the Cogilnic River watershed was selected. Interim steps included the watershed delineation aimed to identify the subwatersheds and the Hydrological Response Units (small entities with the same characteristics of hydrologic soil type, land use and slopes). To address these tasks, the land cover, soil and slope layers, based on the Digital Elevation Model, were integrated in the SWAT environment. These thematic layers, alongside with long-term information on local monthly maximum and minimum temperatures and precipitation, enabled reflecting the differences in hydrological conditions and defining the watershed runoff. However, the validation of the modelling outputs, carried out through comparison of a simulated water yield from the studied watershed with actual Cogilnic streamflow measures, observed in 2010-2012, showed a great discrepancy between these parameters caused by anthropogenic loading on this small river. Thus, a 'classical' SWAT modelling needs to account for real environmental conditions and water use in the study area.
\end{abstract}

Keywords: Moldova, SWAT, streamflow, water yield modelling

\section{Introduction}

The movement and storage of water at a watershed scale is a complex system affected by climatic, geologic, soil, land use, anthropogenic and other factors. The nature of the processes inherited in surface and subsurface hydrology is usually investigated by hydrologic models simulating these processes over different time intervals, scales and physiographical conditions. In recent years, a number of conceptual hydrological simulation models have been developed and are increasingly used by hydrologists and water resource managers to understand and address the extensive array of water resource problems, including those related to the watershed, streamflow and reservoir management, as well as to human activities that affect these processes. Numerous review studies provide comparisons of either complete modelling hydrologic packages or their specific components, with varying levels of input/output data and structural complexity $[1,2,3,4,5]$.

Among the most widely used watershed and river basinscale models is the Soil and Water Assessment Tool (SWAT) based on development of its individual components that it utilized over multiple decades [6,7]. The history of the SWAT development and the following enhancements, from its first version that emerged in the early 1990s (version 94.2) to the latest versions, is well described by Arnold et al.

\footnotetext{
*E-mail address: rcorobov@gmail.com ISSN: 1791-2377 @ 2016 Eastern Macedonia and Thrace Institute of Technology. All rights reserved.
}

[8]. Due to its comprehensive nature, strong support and open access status, the SWAT model has proven to be highly flexible in addressing a wide range of water resource problems. Hundreds of SWAT-related papers were presented at numerous scientific meetings and in dozens of articles have been published in peer-reviewed journals. The widespread use of SWAT in comparison with several other leading hydrologic models was demonstrated by Refsgaard et al. [2]. In addition, a good review of the SWAT extensive testing for hydrologic modelling on different spatial scales is provided by Zhan et al. [5].

Thus, undoubtedly, this model, described in detail by Arnold et al. [9], Neitsch et al. [10] and Winchell et al. [11], has proven to be an effective tool for assessing water resource for a wide range of scales and environmental conditions across the globe (see e.g. $[12,13,14]$ ) and has gained international acceptance as a robust interdisciplinary watershed modelling tool. However, certain weaknesses encountered in some of the SWAT outputs clearly show that expanded testing of this model, initially developed and adapted to specific USA conditions, is needed. As Gassman et al. [7] noted, the SWAT users are to bear in mind that modelling results should reasonably reflect the actual hydrologic processes. This recommendation is especially important for Moldova where anthropogenic pressures on water resources, caused by their poor management, negatively affect the quantity and quality of water supply, necessary for the sustainable functioning of the national economy and providing the necessary ecosystem services. The correct use of the up-to-date hydrological modeling 
allows to quantify these losses and to plan timely the appropriate response measures.

The goal of this study was to examine the suitability of the SWAT model for the investigation of water yields in those areas of Moldova where water resources are presented mainly as small anthropogenically modified rivers.

\section{Study area}

For the SWAT validation, the Cogilnic River watershed was selected. This river is one of Moldova's typical small rivers, which originates in the Moldavian Central Upland (also known as Codrii) and falls into the Black Sea between the Dniester and Danube River Deltas. For the study, the upper part of the Cogilnic River watershed $(U C R W)$ was chosen, from its source to the hydrological post Hincesti where monitoring observations of the streamflow are carried out (Fig. 1). The drainage area of UCRW is about $243 \mathrm{~km}^{2}$; a perennial streamflow is generated at the highest elevations in its northern part.

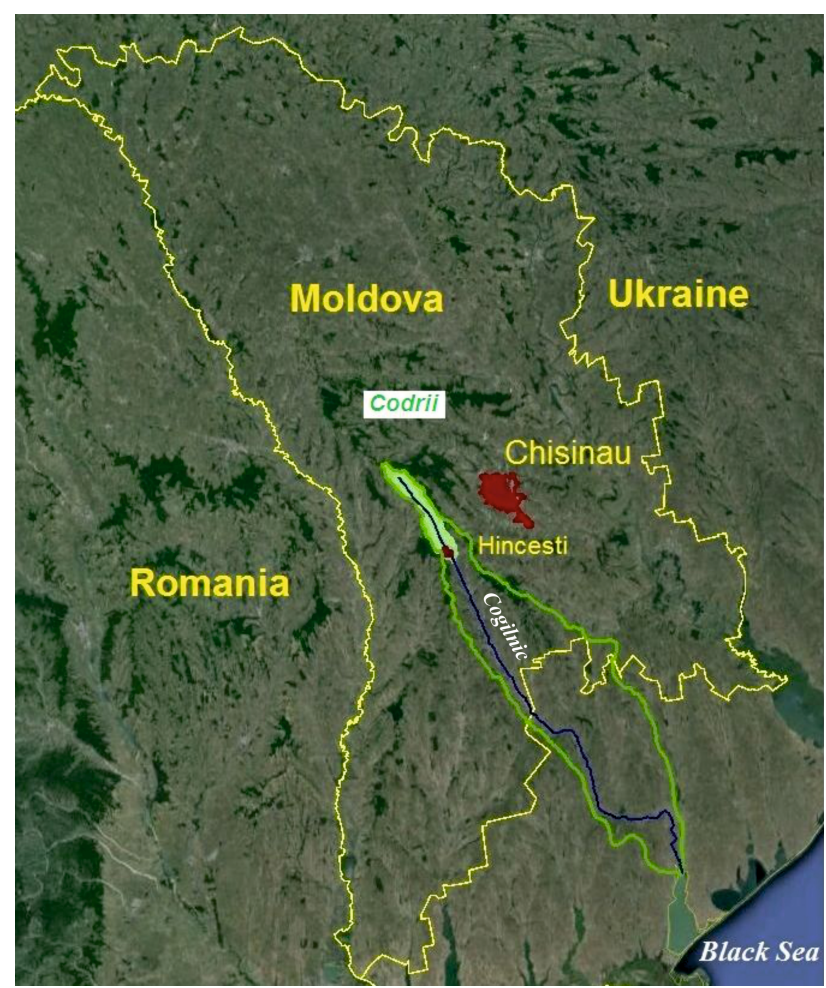

Fig. 1. Upper watershed (shaded area) of the Cogilnic River basin (green contour). Scale 1:2000 000.

The UCRW landscape has been formed by marine and continental deposits of Miocene (clays, marls, limestones, sands, sandstones and Quaternary loesses). Now the landscape is characterized by gently to moderately hills, with average elevation of about $242 \mathrm{~m}$, varying from 393.7 in the Cogilnic River source to $115.7 \mathrm{~m}$ in Hincesti. The length of its main channel in the studied area is $45.6 \mathrm{~km}$, with a mean channel slope of about $6.1 \mathrm{~m} / \mathrm{km}$ and surface runoff generally moving toward the southeast. However, the Cogilnic River drainage area is a very poor of water sources, and sometimes its tributaries dry up, especially in rainless periods and on its higher parts. Due to the absence of continuous stream flow, they usually freeze in cold winters.
Some reaches are blocked by dams, forming approximately 20 artificial reservoirs, with areas from 0.1 to 10.6 ha, shallow depths (1-3 $\mathrm{m}$ at the dams) and relatively small volumes. A main source of their supply is snowmelt water and precipitation that is significantly reduced in dry years. Ground water is generally located at a depth of $5 \mathrm{~m}$; in some cases it may occur at smaller depths $(1.5-2.0 \mathrm{~m})$ and even on the surface, causing landslides and other exogenous processes. The most common geomorphologic units in the watershed are upland areas $(89.2 \%)$ followed by lowlands (10.8\%). A general exposition, determined by the relief and water flow, is northeastern and southwestern with slopes varying from $0-2^{\circ}$ (plateau, meadows) to $21^{\circ}$.

The UCRW climate is temperate continental with short mild winters and long hot summers. Here, based on historical observations at the nearest Codrii weather station in the two decades with measurements (1993-2012), the mean annual air temperature was $9.5^{\circ} \mathrm{C}$, with mean winter and summer values of $1.3^{\circ} \mathrm{C}$ and $20.2^{\circ} \mathrm{C}$, respectively. The average annual total precipitation in this period was 580 $\mathrm{mm}$, ranging from $400 \mathrm{~mm}$ to $760 \mathrm{~mm}$. About $70 \%$ of total precipitations occur during the warm season (April to October), only about $10 \%$ - falls as snow. Such climatic conditions favor the growth and development of plant species, however dry spells in warm seasons, sometimes lasting from 10 days to 2.5 months, cause a reduction in a surface runoff, water deficit and problems in water supply.

\section{Material and methods}

\subsection{Initial material}

To accomplish the main goal of the study, its research approach involved the application of SWAT to simulate the monthly and annual runoffs of the UCRW watershed. Afterwards, the modelled runoff was compared with the observed Cogilnic River streamflow at Hincesti hydrological post from 1 January 2010 to 31 December 2012 (Tab. 1). Usually, such databases with long-term time series of streamflow and climate data provide an essential foundation for calibration and validation of the conceptual models designed to simulate watershed water yields.

A watershed's climate provides moisture and energy inputs that control water balance and determine the relative importance of different components in a hydrological cycle $[10,11]$. The climatic variables required by SWAT consist of daily precipitation, maximum/minimum air temperature, solar radiation, wind speed and relative humidity. The SWAT allows inputting these variables from the daily observations or their simulations from averaged monthly values. Because of practically no free access to daily weather information in Moldova, for the simulation of the UCRW climatic conditions the historical three-year (20102012) monthly observations of mean maximum and minimum air temperatures, and precipitation at the Codrii weather station were used (Tab. 2), considering them as uniform for the whole study area. The standard deviations (Sd) of monthly temperatures, necessary as one input for modelling, were based on 20-yrs observation period (19932012). The other weather input parameters were simulated by Weather Generator (WGEN) that is embedded in the SWAT. 
Table 1. Monthly statistics of the Cogilnic River streamflow in 2010-2012 (m³ $/ \mathrm{s})$

\begin{tabular}{|c|c|c|c|c|c|c|c|c|c|c|c|c|c|}
\hline \multirow{2}{*}{ Year } & \multirow{2}{*}{ Statistics } & \multicolumn{12}{|c|}{ Months } \\
\hline & & 1 & 2 & 3 & 4 & 5 & 6 & 7 & 8 & 9 & 10 & 11 & 12 \\
\hline \multirow{3}{*}{2010} & Mean & 0.075 & 0.17 & 0.17 & 0.15 & 0.31 & 0.17 & 0.17 & 0.026 & 0.072 & 0.11 & 0.12 & 0.21 \\
\hline & Max & 0.22 & 0.50 & 0.22 & 0.39 & 1.13 & 1.51 & 1.29 & 0.22 & 0.45 & 0.19 & 0.19 & 1.09 \\
\hline & Min & 0.028 & 0.035 & 0.13 & 0.10 & 0.16 & 0.014 & 0.030 & 0.008 & 0.022 & 0.060 & 0.070 & 0.080 \\
\hline \multirow{3}{*}{2011} & Mean & 0.20 & 0.21 & 0.19 & 0.31 & 0.18 & 0.28 & 0.15 & 0.080 & 0.057 & 0.13 & 0.11 & 0.14 \\
\hline & Max & 0.52 & 0.48 & 0.23 & 1.17 & 0.24 & 2.54 & 0.32 & 0.10 & 0.070 & 0.21 & 0.12 & 0.18 \\
\hline & Min & 0.13 & 0.15 & 0.16 & 0.16 & 0.13 & 0.10 & 0.10 & 0.058 & 0.052 & 0.094 & 0.094 & 0.11 \\
\hline \multirow{3}{*}{2012} & Mean & 0.096 & 0.095 & 0.17 & 0.17 & 0.12 & 0.11 & 0.15 & 0.15 & 0.15 & 0.16 & 0.073 & 0.17 \\
\hline & Max & 0.11 & 0.13 & 0.28 & 0.22 & 0.14 & 0.11 & 0.26 & 0.15 & 0.15 & 0.26 & 0.13 & 0.30 \\
\hline & Min & 0.089 & 0.088 & 0.11 & 0.14 & 0.11 & 0.11 & 0.11 & 0.15 & 0.15 & 0.12 & 0.041 & 0.12 \\
\hline
\end{tabular}

Table 2. Monthly weather observation at Codrii weather station in 2010-2012

\begin{tabular}{|c|c|c|c|c|c|c|c|c|c|c|c|c|c|}
\hline \multirow{2}{*}{ Year } & \multicolumn{12}{|c|}{ Month, ${ }^{\circ} \mathrm{C}$} & \multirow{2}{*}{ Annual } \\
\hline & 1 & 2 & 3 & 4 & 5 & 6 & 7 & 8 & 9 & 10 & 11 & 12 & \\
\hline \multicolumn{14}{|c|}{ Mean monthly maximum temperature, ${ }^{\circ} \mathrm{C}$} \\
\hline 2010 & $-2,1$ & 2,7 & 9,7 & 16,8 & 23,0 & 26,2 & 28,8 & 30,7 & 21,3 & 11,8 & 15,2 & 1,6 & 15,5 \\
\hline 2011 & 2,2 & 0,8 & 9,8 & 15,4 & 22,9 & 25,7 & 28,5 & 27,7 & 25,2 & 14,9 & 7,2 & 6,2 & 15,5 \\
\hline 2012 & 1,2 & $-3,4$ & 9,5 & 19,8 & 25,1 & 30,0 & 33,3 & 30,0 & 26,1 & 18,0 & 9,7 & 0,3 & 16,6 \\
\hline Sd & 2,83 & 3,34 & 2,84 & 1,89 & 2,24 & 1,88 & 2,09 & 1,66 & 2,63 & 1,75 & 2,80 & 2,93 & 0.9 \\
\hline \multicolumn{14}{|c|}{ Mean monthly minimum temperature, ${ }^{\circ} \mathrm{C}$} \\
\hline 2010 & $-8,0$ & $-3,3$ & $-1,5$ & 4,1 & 10,4 & 14,6 & 16,0 & 16,4 & 9,4 & 3,0 & 6,2 & $-5,7$ & 5,1 \\
\hline 2011 & $-5,3$ & $-6,0$ & $-1,9$ & 3,1 & 8,7 & 13,4 & 14,5 & 12,7 & 9,9 & 2,4 & $-1,6$ & $-1,3$ & 4,1 \\
\hline 2012 & $-5,6$ & $-12,7$ & $-1,2$ & 5,8 & 11,0 & 14,5 & 16,2 & 14,6 & 10,9 & 6,7 & 3,0 & $-6,7$ & 4,7 \\
\hline Sd & 2,48 & 3,19 & 1,81 & 1,50 & 1,29 & 1,05 & 1,03 & 0,97 & 0,92 & 1,42 & 2,72 & 3,24 & 0,58 \\
\hline \multicolumn{14}{|c|}{ Precipitation, $\mathrm{mm}$} \\
\hline 2010 & 78,5 & 63,9 & 23,8 & 30,6 & 68 & 86,7 & 104,4 & 70,6 & 68,5 & 58,2 & 36,5 & 69,8 & 760 \\
\hline 2011 & 27,5 & 20,4 & 10,1 & 74,4 & 86,9 & 176,5 & 52,7 & 26,9 & 13,1 & 43,6 & 1,7 & 14,7 & 549 \\
\hline 2012 & 20,3 & 55,6 & 21,2 & 42 & 44,8 & 13,9 & 97,5 & 35,3 & 34,6 & 38,8 & 29,2 & 129,4 & 563 \\
\hline
\end{tabular}

\subsection{Methodological approach}

The ArcSWAT interface for the SWAT [11], which has evolved from the AVSWAT2000 and ArcView extensions developed for its earlier releases, applies a hydrologic modelling approach that utilizes spatially distributed climate, topography, soils as well as land use and land management practices. The simulation of watershed hydrology is separated into a land phase, which controls the amount of water loading to the main channel, and an in-stream or routing phase presenting the movement of water through a watershed channel network to the outlet [8]. For modelling purposes, the watershed, through the procedure of delineation, is partitioned into subwatersheds, connected by a stream network, and into hydrologic response units (HRUs) - small entities with the same characteristics of hydrologic soil type, land use and slopes. This delineation allows SWAT to reflect spatial heterogeneity in the watershed. Lumping the similar soil and land use areas into a single unit through HRU delineation, minimizes also the computational costs of simulations [5]. On the other hand, this approach requires detailed spatial input data describing all land use, land cover and soil characteristics, which are available from various information sources, and their distribution within the watershed [9].

\subsubsection{Watershed delineation}

The UCRW delineation for identifying the reaches and subwatersheds was carried out in the ArcSWAT environment, using the Digital Elevation Model (DEM) built on topographical data (scale 1:25,000), digitized in the Moldavian Academy of Sciences [15]. Vectorization of the topographic maps resulted in a pixel size of $10 \times 10 \mathrm{~m}$ that was suitable for a hydrological analysis.

Reaches were defined as parts of the river whose drainage areas were more than a specified threshold value, or a critical source area that defines a minimum upstream subwatershed, which is required to form the origin of a stream [11]. Based on the study area, the selected threshold value was 500 ha. According to this criterion and the level of 
relief roughness, 27 sub-basins were automatically defined on the reaches upstream of Hincesti hydrological post (Fig. 2). The lengths of the reaches were between about $0.3 \mathrm{~km}$ and $10.2 \mathrm{~km}$, with the mean value of $3.9 \mathrm{~km}$. The location of the selected hydrological post coincides with the UCRW outlet, or the point where streamflow exits this watershed and therefore reflects its entire drainage network. This is useful to compare modeled and measured flows.

The results of the delineation are shown in Fig. 2.
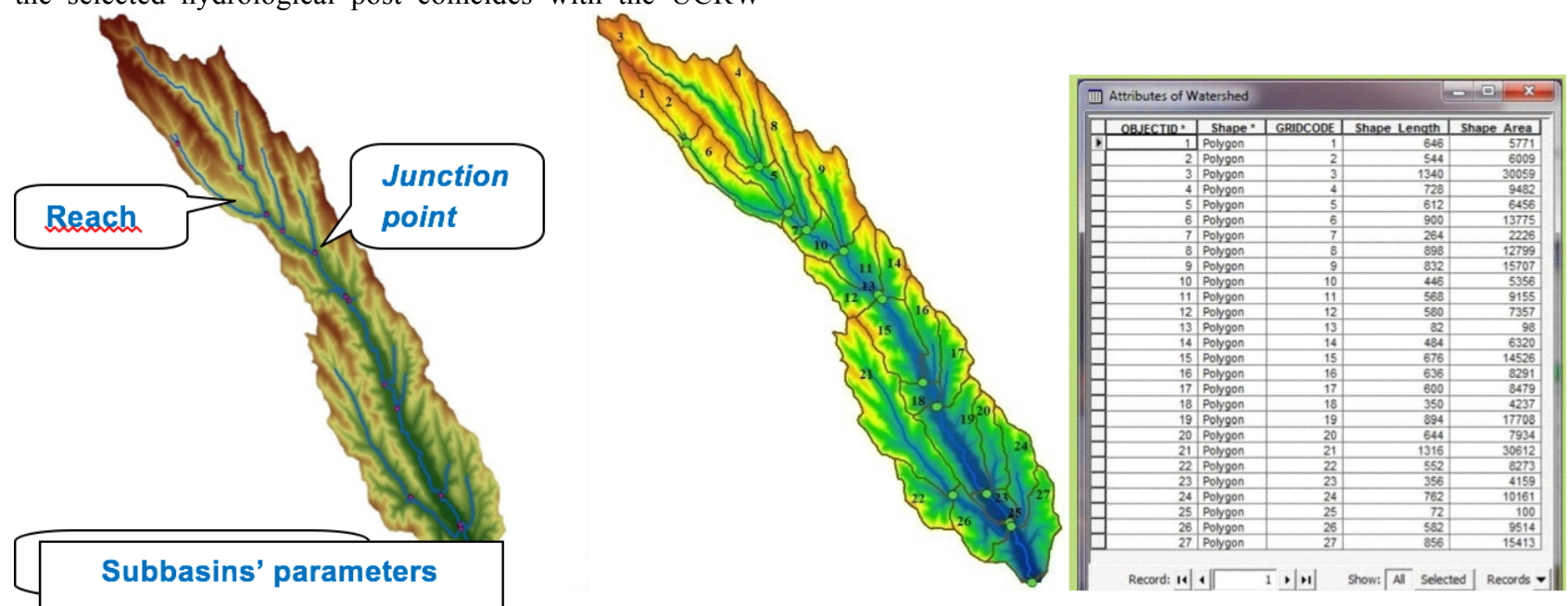

Fig. 2. The Cogilnic River watershed's drainage network overlapped with the DEM (left), its sub-basins (centre) and their parameters (right). The sub-basin outlets were defined as stream junction points.

\subsubsection{HRU definition}

Subdivision of the UCRW into HRUs enables reflecting the differences in hydrological conditions for different localities. HRUs were determined by the dominant land-use category, soil type and slope class within subwatersheds [11]. Due to the relatively small areas of delineated subwatersheds, only a single HRU was identified for each, and thus 27 HRUs were developed for the UCRW's part above the hydrological post Hincesti where water yield was measured. Subwatershed/HRU characteristics were obtained from the GIS's vector data layers.

Although Moldova is not included in the land cover vector files of the CORINE (Co-ORdinated INformation on the Environment; http://www.eea.europa.eu/publications/COR0-landcover), the codes of this database were used to create the UCRW watershed land-use maps (Fig. 3). These maps were built based on the interpretation of satellite images with a following clarification on the orthophoto images with a resolution of $1 \mathrm{~m}$. Then these materials were generalized and translated in a raster format. In the CORINE codes the
UCRW land-use was distributed as follows: Residential $(U R B N)$ - 1,969 ha; Orchard (ORSD) - 5,217 ha; Pastures (PAST) - 510 ha; Complex cultivation patterns (AGRL) 8,848 ha; Broad leaved forests (FRSD) - 7,719 ha; Water (WATR) - 34 ha.

The Soils of the UCRW were classified according to the World Reference Base for Soil Resources, deposited as the Food and Agriculture Organization (FAO) Corporate Document Repository at the FAO website [16], and were grouped into six classes and areas: Greyzem $(G R)-4,590$ ha; Chernozem (CH) - 16,677 ha; Fluvisol (FL) - 900 ha; Gleysol (GL) - 1,649 ha; Vertisol (VR) - 432 ha, and Luvisol $(L V)-50$ ha (Fig. 3). The available soil maps (scale 1:50 000) were generalized and converted to a raster format, and served as a basis for the vector version of the UCRW soil map.

The average slope of UCRW is about 6.9 degrees. Four categories - less than $2^{0}, 2.0^{\circ}$ to $7.0^{\circ}, 7.0^{\circ}$ to $14.0^{\circ}$ and $14.0^{\circ}$ to $21^{0}$ - were used to capture all slopes, from low to high, occupying $12,40,45$, and $3 \%$ of this watershed area, respectively (Fig. 3).

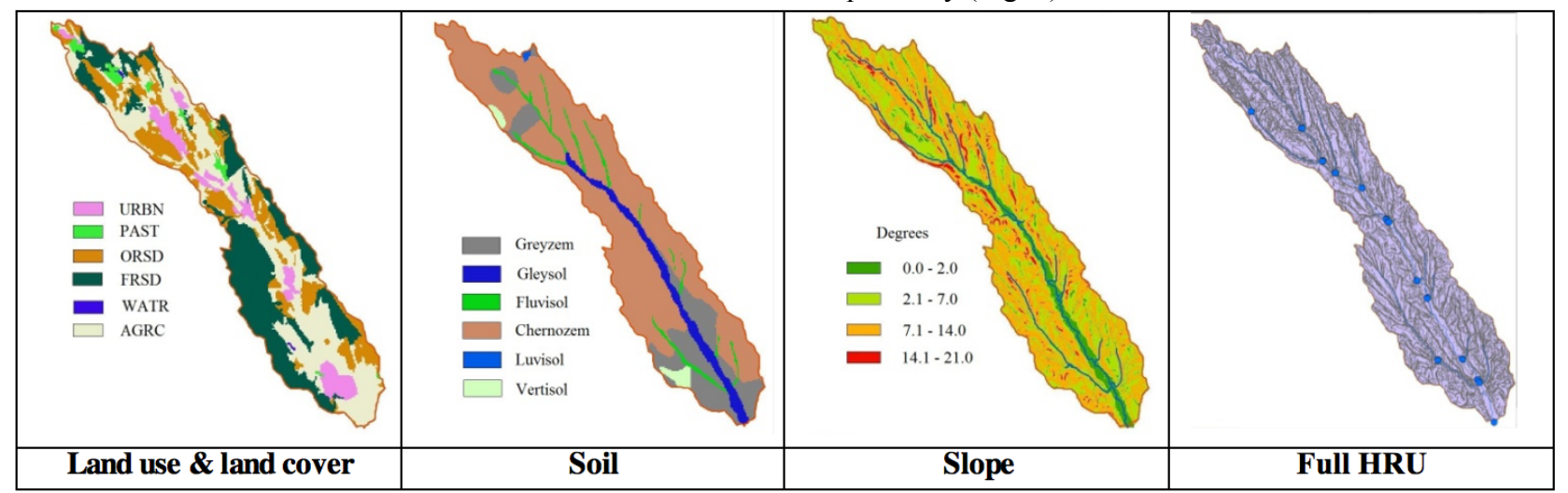

Fig. 3. Three thematic layers for identification of hydrological response units (HRUs) and the result of their overlay 
Reclassification of land use, soils and slopes maps into SWAT layers enabled their overlay. This procedure resulted in a new layer called FullHRU, which was added to the SWAT geodatabase. Surface runoff and base flow were predicted separately for each HRU and routed to obtain a total water yield.

\section{Results of modelling}

The annual results of the three SWAT simulations are shown in Tab. 3. These standard outputs contain summary information on the model run, including the watershed-level statistics that help to determine whether the SWAT model is producing valid results.

Table 3. Results of the UCRW annual water yield simulation for 2010-2012

\begin{tabular}{cccccccccc}
\hline \multirow{2}{*}{ Year } & \multicolumn{8}{c}{ SWAT Outputs, mm } \\
\cline { 2 - 10 } & PREC & SURQ & LATQ & GWQ & LATE & SW & $E T$ & PET & W. YIELD \\
\hline 2010 & 759.6 & 82.2 & 51.9 & 56.1 & 86.5 & 32.3 & 297.1 & 852.6 & $\mathbf{1 9 2 . 8}$ \\
2011 & 549.0 & 53.1 & 37.6 & 26.2 & 49.3 & 32.4 & 246.5 & 853.3 & $\mathbf{1 1 8 . 5}$ \\
2012 & 563.4 & 46.5 & 64.0 & 71.3 & 132.0 & 35.0 & 287.6 & 847.8 & $\mathbf{1 8 5 . 0}$ \\
\hline
\end{tabular}

Abbreviations: RREC - average amount of simulated precipitation; $S U R Q$ - amount of surface runoff contribution; $L A T Q$ - lateral subsurface flow contribution; $G W Q$ - ground water contribution; LATE - water percolation past bottom of soil profile; $S W$ - amount of water stored in soil profile; $E T$ - actual evapotranspiration; $P E T$ - potential evapotranspiration; WATER YIELD - watershed runoff to streamflow.

For each time step, SWAT calculates the amount of water that infiltrates into the soil and evaporates; the rest of water becomes runoff that occurs whenever the rate of water application to ground surface exceeds the rate of infiltration [10]. From this viewpoint, the parameters $S U R Q$ (amount of surface runoff contribution), $L A T Q$ (lateral subsurface flow contribution) and $G W Q$ (ground water contribution) define runoff, or the loading from HRUs to the main stream, while the rest parameters define infiltration and evapotranspiration. Average watershed values are a weighted sum of all HRUs' contribution to the streamflow and soil profile before any channel routing is simulated; the annual averages provide users with the basic understanding of the watershed water balance.

A quick analysis of the simulation results (Tab. 3) gives some formal reasons to consider them as quite correct. In particular, the water yield exceeds infiltration about 2.3 times in 2010-2011 and about 1.8 times in 2012 that was an extremely dry year in Moldova. The ratio of potential evapotranspiration to precipitation changes from 0.39 to 0.51 that is somewhat smaller than its averaged value, for example, for the US $(\sim 0.62)$, but US climate overall is warmer than Central Moldova's climate. However, the SWAT as the comprehensive river basin model contains a large number of input parameters used to describe spatially distributed water movement through a watershed system, and due to this complexity it requires an additional parameterization and calibration.

\section{SWAT validation and calibration}

In practice, the main objective of hydrologic model calibrations is to receive the best agreement between observed and simulated values, and this process is performed by way of selecting the values of a model's parameters addressing this criterion. A final conclusion can only be achieved by the model validation through direct comparison of simulated outputs with the real runoff to the main stream.

The values of the Cogilnic River observed streamflow are shown in Tab. 1. To compare them with the simulated runoff from a corresponding subwatershed, they were recalculated from $\mathrm{m}^{3} / \mathrm{sec}$ into monthly and annual values, expressed in $\mathrm{m}^{3}$. In turn, the simulated SWAT Water Yields, initially expressed in $\mathrm{mm}$ (Tab. 3), were also recalculated in $\mathrm{m}^{3}$ through multiplying them by the watershed area expressed in $\mathrm{m}^{2}$. As one can see from the comparison of simulations and observations (Tab. 4), the discrepancy between them is very significant and cannot be neglected. For example, if to express the observed annual stream flows as a percentage of simulated water yields, they amount to only 9.9, 18.5 and 9.6 percent for 2010, 2011 and 2012, respectively. These differences are even greater when comparison is done on a monthly basis, thus necessitating the SWAT calibration.

Usually, any calibration procedure is targeted at better adjusting of the model to local conditions, thereby reducing its inherent uncertainty. At the same time, the calibration of watershed models is complicated by a necessity to estimate a large number of parameters and coefficients. Only in this case, a set of their values, which generally represents only one possible combination, can produce a response similar to that observed [17]. The comprehensive overview of all key facets required for an ideal SWAT calibration and validation is presented by Arnold et al. [8] who considered a river stream flow as a good example of a process-based calibration. Processes, which take place in the streamflow formation, are comprised of the water balance in the land phase of the hydrology, including ET, lateral and return flow, surface runoff, channel transmission losses, deep aquifer recharge, etc. If data are available for each of these processes, they can be individually calibrated.

The manual calibration is usually performed by changing the values of SWAT input parameters that aims to produce outputs within a certain range of measured data. Since SWAT simulates multiple interactions in the hydrological process, many variables impact these interactions. As a result, any changes in surface runoff trigger corresponding changes not only in components of the water balance but also, for example, in plant growth and, consequently, in evapotranspiration. Numerous studies have reported different input parameters used for the SWAT calibration $[3,4,5,8,17]$. For example, Arnold et al. [8] summarized calibrated parameters that had been used in 64 studies; they 
also emphasised that most manual calibration methods have started with a water balance and streamflow.

Table 4. Comparison of the Cogilnic River observed streamflow $(S)$ and its watershed simulated runoff $(R)$ (the both in $\mathrm{m}^{3}$ ) as their ratio $(R / S)$

\begin{tabular}{cccccrrrrr}
\hline \multirow{2}{*}{ Month } & \multicolumn{3}{c}{$\mathbf{2 0 1 0}$} & \multicolumn{1}{c}{$\boldsymbol{2 0 1 1}$} & & \multicolumn{2}{c}{$\mathbf{2 0 1 2}$} \\
\cline { 2 - 9 } & $\boldsymbol{S}$ & $\boldsymbol{R}$ & $\boldsymbol{R} / \boldsymbol{S}$ & $\boldsymbol{S}$ & $\boldsymbol{R}$ & $\boldsymbol{R} / \boldsymbol{S}$ & \multicolumn{1}{c}{$\boldsymbol{S}$} & $\boldsymbol{R}$ & $\boldsymbol{R} / \boldsymbol{S}$ \\
\hline 1 & 202176 & 0 & 0,0 & 544320 & 0 & 0,0 & 256003 & 0,0 \\
2 & 416189 & 2430 & 0,0 & 499392 & 2430 & 0,0 & 238205 & 1579364 & 6,6 \\
3 & 468288 & 10895178 & 23,3 & 520992 & 5364976 & 10,3 & 443232 & 3591230 & 8,1 \\
4 & 400896 & 1251342 & 3,1 & 796608 & 515115 & 0,6 & 435456 & 2322879 & 5,3 \\
5 & 832896 & 403345 & 0,5 & 482976 & 177375 & 0,4 & 322272 & 840707,3 & 2,6 \\
6 & 437357 & 123919 & 0,3 & 733536 & 48596 & 0,1 & 285120 & 918460,6 & 3,2 \\
7 & 465350 & 12068767 & 25,9 & 389664 & 9077695 & 23,3 & 400896 & 9179747 & 22,9 \\
8 & 70157 & 6633327 & 94,6 & 214618 & 4077188 & 19,0 & 401760 & 6239701 & 15,5 \\
9 & 186624 & 4492682 & 24,1 & 145930 & 2665480 & 18,3 & 388800 & 6174096 & 15,9 \\
10 & 291341 & 1739730 & 6,0 & 338688 & 894163 & 2,6 & 415584 & 2837995 & 6,8 \\
11 & 310522 & 4072328 & 13,1 & 278554 & 2206249 & 7,9 & 189389 & 5095270 & 26,9 \\
12 & 558490 & 5170593 & 9,3 & 368064 & 3766175 & 10,2 & 449280 & 6164377 & 13,7 \\
Year & $\mathbf{4 6 4 0 2 8 5}$ & $\mathbf{4 6 8 5 3 6 4 1}$ & $\mathbf{1 0 , 1}$ & $\mathbf{5 3 1 3 3 4 1}$ & $\mathbf{2 8 7 9 3 0 1 2}$ & $\mathbf{5 , 4}$ & $\mathbf{4 2 2 5 9 9 7}$ & $\mathbf{4 3 9 6 9 4 8 0}$ & $\mathbf{1 0 , 4}$ \\
\hline
\end{tabular}

zero means that this month simulated runoff was absent (no precipitation) or close to zero

Calibration parameters concerning a streamflow are usually divided into those governing surface runoff and those governing subsurface runoff, or baseflow $[3,8]$.

The most popular from the first group is $C N 2$ - an initial SCS runoff curve number for moisture condition II; the second group includes $S O L \_A W C$ - an available water capacity of the first soil layer ( $\mathrm{mm}$ water/mm soil) and $E S C O$ - a soil evaporation compensation factor. According to the SWAT documentation [9,10], CN2 is an empirical parameter, developed by the US Soil Conservation Service (SCS); it is based on an area's hydrologic soil groups, land use and land cover types, and hydrological conditions. This parameter computes runoff depth from total rainfall depth and is widely used as an efficient method for determining the approximate amount of direct runoff from a rainfall event in a particular area, mainly for small catchments and hill slope plots. ESCO adjusts the depth distribution for evaporation from the soil to account for the effect of capillary action, crusting, and cracks; the ESCO reduction leads to more modelled extraction of the evaporation demands from the lower soil levels [10].

The example of our surface runoff calibration through changing the CN2 is shown in Tab. 5. As it can be seen from the table, with 10, 20 and $30 \%$ reduction of $C N 2$, the surface runoff is also respectively reduced. However, Water Yield varies to a little degree because of a corresponding proportional increase in subsurface runoff. In other words, we observe a simple redistribution of the water yield components. Even at $30 \%$ reduction of $C N 2$, the water yield is reduced within the $5 \%$ limits.

Table 5. Change of the surface runoff of the Cogilnic River watershed at $10 \%$ sequential decrease of the $C N 2{ }^{*}$

\begin{tabular}{ccccccccccccc}
\hline \multirow{2}{*}{ CN2 } & \multicolumn{9}{c}{$\mathbf{2 0 1 0}$} & \multicolumn{1}{c}{$\mathbf{2 0 1 1}$} & \multicolumn{4}{c}{$\mathbf{2 0 1 2}$} \\
& SURQ & LATQ & GWQ & Yield & SURQ & LATQ & GWQ & Yield & SURQ & LATQ & GWQ & Yield \\
\hline $\mathbf{7 8 . 8}$ & 131.9 & 70.9 & 100.9 & 307.7 & 41,5 & 62.1 & 85.4 & 193.1 & 43.5 & 61.9 & 84.4 & 193.4 \\
$\mathbf{7 1 . 0}$ & 91.5 & 77.6 & 128.8 & 303.0 & 16.3 & 66.6 & 101.0 & 188.8 & 190.0 & 66.8 & 90.1 & 191.2 \\
$\mathbf{6 3 . 1}$ & 69.8 & 81.1 & 144.2 & 300.8 & 6.4 & 68.5 & 107.2 & 187.2 & 6.5 & 68.3 & 106.5 & 186.4 \\
$\mathbf{5 6 . 2}$ & 55.4 & 83.3 & 154.7 & 299.6 & 4.2 & 69.0 & 108.7 & 187.0 & 4.0 & 68.8 & 108.2 & 186.2 \\
\hline
\end{tabular}

* an initial runoff curve number for moisture condition II

A similar pattern was observed when $S O L A W C$ and ESCO were changed.

These results support real life experiences that the SWAT capabilities are quite limited in relation to small rivers, especially to those exposed to substantial anthropogenic changes. The model calibration in these cases is not able to take into account all factors affecting their runoff, thereby causing the inevitable bias in its evaluation.
The discrepancy between simulations and observations is very significant and very difficult to be eliminated by any calibration.

Indeed, all small rivers in Moldova are extremely polluted and heavily disturbed by anthropogenic activities, in some case leading to their complete drying [18]. Today's situation is caused by an illegal creation of numerous ponds in their basins (often without any project documentation), by 
water withdrawal for personal needs of local people and tenant farmers, as well as by high-water dams and uncontrolled landfills on river banks. As a result, the channels of the small rivers are changing, they are losing their water sources and tributaries, with precipitation and snow-melt water either evaporating or infiltrating to different depths. Moreover, drying of small rivers affects

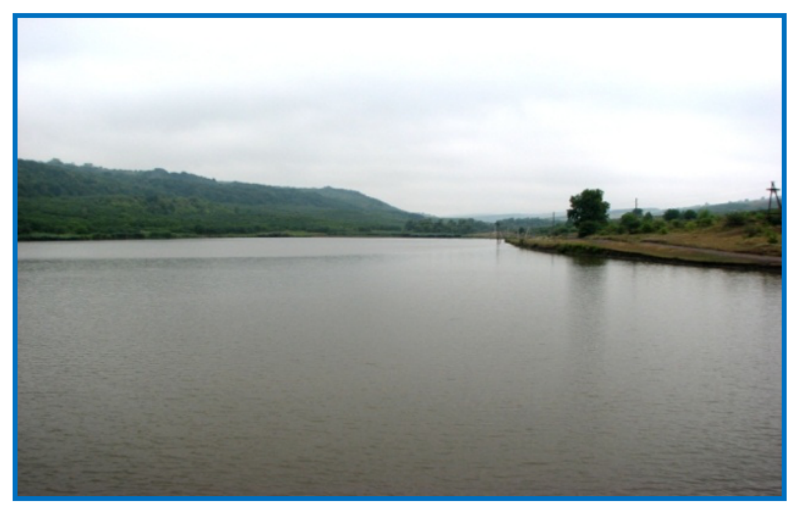

A pond in the river bed seriously the general state of the watershed ecosystems, thus changing the plant cover and evapotranspiration conditions.

In particular, the calculations, performed by Casac \& Lalikin [18], showed that approximate reductions of the Cogilnic River streamflow due only partially to these anthropogenic factors are: due the land treatment - up to $20 \%$; artificial reservoirs - 10-15\%; irrigation $-4-5 \%$; urbanization $-10 \%$ (e.g., see Fig. 4).

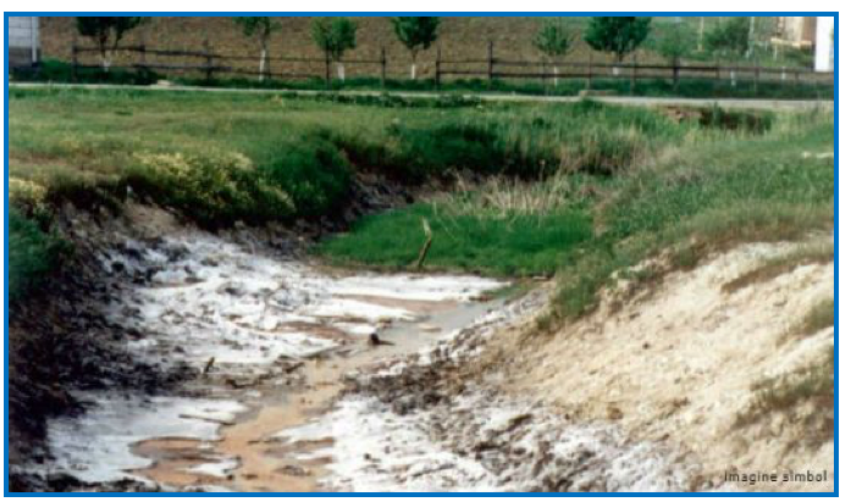

Domestic pollution and complete drying of a tributary

Fig. 4. Two examples of the anthropogenic disturbance of the Cogilnic River upper watershed runoff

\section{Conclusion}

The findings of this study provide certain evidence that SWAT can be an effective tool for modelling watershed runoff. However, the specific weaknesses encountered in some of the SWAT output contingencies support clearly the conclusions of Gassman et al. [6] that the expanded testing of modelling results is needed in order they could reasonably reflect actual hydrological processes. The SWAT is less powerful when it is used to model the streamflow of small anthropogenically altered streams. In these cases, the modeled amount of water yields including a surface runoff and baseflow, which eventually enter to the river stream based on the SWAT outputs, does not reflect some additional external factors. Among these factors there are diverted and return flows to and from the agricultural, municipal and industrial usage, as well those amounts, which are stored in artificial ponds or are lost due other human activities. Thus, SWAT modeling for small heavily modified rivers yields a certain hypothetic runoff from the watershed that can be real only for "a pristine environment", e.g. for natural reserves where any external intervention is forbidden. Otherwise, the careful validation of this model must be accompanied by the evaluation of a bias, which is caused by anthropogenic factors and cannot be eliminated during calibration.

Taking into consideration the anthropogenic factors is especially important in modelling extreme runoffs, often followed by high waters and floods, because in many cases these simulations are based on the long-term mean values. On the one hand, an overestimation of water yields leads to the unavoidable overstatement of the hydrological hazard levels and, consequently, of the costs to confront them. On the other hand, any uncertainties in hydrological modeling distorts sound planning of water use in a river basin, especially in extreme dry situations, which are becoming more frequent and more intensive due to climate change. So, the very dry late summer of 2015 in Moldova has caused a necessity to cease temporarily the planned irrigation of agricultural crops due to a critical reduction of water levels in the main rivers.

Finally, Moldova, like most of small countries, does not have its own hydrological models, and therefore it is forced to use the well-established foreign ones. In addition to the general problems in differentiating the runoff generation processes that are inherent in these models, their default parameters were developed primary to fit rainfallrunoff relations in the countries of their origin, and thus they are not necessarily accurate for other physiographic conditions. As a result, any of such models need to be adjusted to national conditions by the testing validation and calibration based on local climatic, hydrological and environmental conditions.

This paper was presented at International Conference titled "Frontiers in Environmental and Water Management", that took place March 19-21st 2015, at Kavala Greece.

\section{Acknowledgement}

The authors thank the EU INTERREG IV "Black Sea Basin Joint Operational Programme 2007-2013" that is responsible for the funding of the project "Utilizing Stream Waters in the Suppression of Forest Fires with the Help of New Technologies" in which framework this research was carried out. The content of this publication is the sole responsibility of its authors and can in no way reflect the views of the European Union. 


\section{References}

1. Daniel, E.B., J.V. Camp, E.J. LeBoeuf, J.R. Penrod, J.P. Dobbins, and M.D. Abkowitz (2011): Watershed modeling and its applications: A state-of-the-art review. Open Hydrol. J. 5:26-50.

2. Refsgaard, J.C., B., Storm, and T., Clausen (2010): Systeme Hydrologique Europeen (SHE): Review and perspectives after 30 years development in distributed physically-based hydrological modelling. Hydrol. Res. 41(5): 355-377.

3. Van Liew, M.W., Arnold, J.G., and Bosch, D.D. (2005): Problems and potential of autocalibrating a hydrologic model. Transactions of the ASAE, 48(3): 1025-1040.

4. Van Liew, M.W., T.L. Veith, D. D. Bosch, and J. G. Arnold (2007): Suitability of SWAT for the Conservation Effects Assessment Project: A comparison on USDA-ARS watersheds. $J$. Hydrol.Eng. 12(2): 173-189.

5. Zhang, X., Srinivasan, R., Van Liew M. (2008): Multi-site calibration of the SWAT model for hydrologic modelling. Transactions of the ASABE 51(6): 2039-2049.

6. Gassman, P.W., Reyes, M.R., Green, C.H. and Arnold, J.G. (2007): The soil water and assessment tool: Historical development, applications, and future research directions. Transactions of the American Society of Agricultural and Biological Engineers 50(4): 1211-125.

7. Gassman, P.W., Sadeghi, A.M., and Srinivasan R. (2014): Applications of the SWAT Model Special Section: Overview and Insights. Journal of Environmental Quality, 8 p.

8. Arnold, J.G., D.N. Moriasi, P.W. Gassman, K.C. Abbaspour, M.J. White, R. Srinivasan, C. Santhi, R.D. Harmel, A. van Griensven, M.W. Van Liew, N. Kannan, M.K. Jha (2012b): SWAT: Model use, calibration and validation. Transactions of the ASABE 55(4): 1491-1508.

15. Zhuk M., Novac S., Syrodoev Gh. (1995): Digital Elevation Model for Republic of Moldova. Computer Science Journal of Moldova 1(4):3-7.

16. IUSS Working Group WRB (2014): World Reference Base for Soil Resources 2014. International soil classification system for naming soils and creating legends for soil maps. World Soil Resources Reports No. 106. FAO, Rome.

17. Van Liew, M.W., and J., Garbrecht (2003): Hydrologic simulation of the Little Washita River experimental watershed using SWAT. J. American Water Resour. Assoc. 39(2): 413426.

18. Casac, V. and Lalikin, N. (2005): Hydrological characteristics of Moldova's small rivers and their anthropogenic change. Chisinau, 208 pp. (in Russian)
9. Arnold, J.G., Kiniry, J.R., Srinivasan, R., Williams, J.R., Haney, E.B. and Neitsch, S.L., (2012a): Soil and Water Assessment Tool, Input/Output File Documentation,Version 2012. Texas Water Research Institute. Technical Report 439, College Station, Texas, US.

10. Neitsch, S.L., Arnold, J.G., Kiniry, J.R. and Williams, J.R. (2011): Soil and Water Assessment Tool - Theoretical Documentation. Version 2009. Grassland, Soil and Water Research Laboratory Agricultural Research Service - Blackland Research Center Texas AgriLife Research; Temple, Texas. 618 pp.

11. Winchell, M., Srinivasan, R., Di Luzio, M., and Arnold, J.G. (2013): ArcSWAT Interface For SWAT 2009: User's Guide. Texas Agricultural Experiment Station (Texas) and USDA Agricultural Research Service (Texas), Temple (Texas).

12. Adeogun, A.G., Sule, B.F., Salami, A.W., Daramola, M.O. (2014): Validation of SWAT Model for Prediction of Water Yield and Water Balance: Case Study of Upstream Catchment of Jebba Dam in Nigeria. International Scholarly and Scientific Research \& Innovation 8(2): 264-270.

13. Kalogeropoulos, K., Chalkias, C., Pissias, E. and Karalis, S. (2011): Application of the SWAT model for the investigation of reservoirs creation, Advances in the Research of Aquatic Environment, Environmental Earth Sciences, Part 1, pp. 71-79.

14. White, E.D., Easton, Z.M., Fuka, D.R., Collick, A.S., McCartney, M., Awulachew, S.B. and Steenhuis, T.S. (2009): A Water Balance-Based Soil and Water Assessment Tool (SWAT) for Improved Performance in the Ethiopian Highlands. In: Improved Water and Land management in the Ethiopians Highlands: Its impacts on Downstream Stakeholders Dependent on the Blue Neal, CP 19 Project Workshop Proceedings, February 5-6, 2009, Addis-Ababa, Ethiopia, pp. 153-158. 